\title{
ESCOLA E TRABALHO INFANTIL SOB A ÓTICA DE ADULTOS
}

\author{
Aline Madia Mantovani ${ }^{1}$; Pedro Pugliesi Abdalla ${ }^{2}$; Anderson dos Santos Carvalho ${ }^{3}$ \\ ${ }^{1}$ Doutora em Educação pela Universidade Estadual Paulista (UNESP), campus de Presidente Prudente, SP. E-mail: alinemadia@hotmail.com \\ ${ }^{2}$ Mestre pelo programa de Pós-Graduação em Educação Física e Esporte (2017) da Escola de Educação Física e Esporte de Ribeirão Preto da \\ Universidade de São Paulo (EEFERP/USP). \\ 3 Doutorando em Ciências - InterUnidades da Universidade de São Paulo (USP). Mestre em Educação Física pela Universidade Metodista (UNIMEP).
}

\section{RESUMO}

O objetivo desse estudo é compreender a relação entre trabalho infantil e escola a partir da fala de adultos com histórico de trabalho infantil, estudantes em turmas de Educação de Jovens e Adultos. Participaram da pesquisa 131 adultos, de ambos os sexos; foi utilizado um questionário, baseado em estudo internacional, que ajudou a traçar o perfil dos participantes, as implicações do trabalho infantil sobre a escolarização e os índices de valorização atribuídos ao fenômeno. Adotou-se como perspectiva teórica analisar o trabalho infantil para além de um viés generalista e universalista, visando o encaminhamento de considerações aprofundadas e embasadas nas perspectivas dos sujeitos. Os resultados apontam que o trabalho infantil, atualmente, encontra-se presente nos mais diversos espaços sociais, ocorre devido aos aspectos sociais e econômicos que perpetuam as desigualdades sociais, impacta positiva e negativamente sobre a vida adulta e reveste-se de características culturais e ideológicas diversas.

Palavras-chave: Trabalho infantil, escola, adultos, aspectos econômicos e implicações sociais.

\section{SCHOOL AND CHILD LABOR UNDER THE OPTICS OF ADULTS}

\begin{abstract}
The purpose of this study is to understand the relationship between child labor and school based on the discourse of adults with a history of child labor, students in Youth and Adult Education classes. 131 adults of both sexes participated in the study; a questionnaire was used, based on an international study, which helped to outline the participants' profile, the implications of child labor on schooling and the valuation indexes attributed to the phenomenon. It was adopted as a theoretical perspective to analyze child labor in addition to a generalist and universalist bias, aiming at the forwarding of in-depth considerations based on the perspectives of the subjects. The results show that child labor is currently present in the most diverse social spaces, due to the social and economic aspects that perpetuate social inequalities, positively and negatively impact on adult life and has cultural and ideological characteristics.
\end{abstract}

Keywords: Child labor, school, adults, economic aspects and social implications.

\section{INTRODUÇÃO}

O trabalho infantil sempre existiu na história da humanidade, mesmo a partir da promulgação de leis e decretos que legislam por sua erradicação, e os elementos que perpassam essas discussões nos levam a debates polissêmicos, que ora o associam a impactos negativos ora a possíveis resultados positivos. Sendo assim, é preciso romper com proposituras que desconsideram a construção cultural do trabalho infantil e o modelo social vigente em que prevalece a desigualdade, priorizando-se 0 ponto de vista do sujeito trabalhador e suas condições objetivas de vida, que encaminham, cada vez mais cedo, para situações de trabalho.
Em termos de definição, no Brasil, consideramos "trabalho infantil" toda e qualquer atividade que se executa antes da idade mínima prevista em lei (14 anos), sobretudo quando esta inserção prejudicar e/ou inviabilizar o usufruto de direitos fundamentais, como escolaridade, lazer, cultura, descanso, saúde e integridade (LIBÓRIO, 2009). Também entendemos como "inserção em trabalho infantil" a presença de crianças e adolescentes em três setores da economia: "doméstico" (na própria casa ou na casa de terceiros), "informal urbano" e "rural" (em fazendas próprias ou para outros proprietários) (MANTOVANI, 2017). 
De acordo com Stropasolas (2012), em todos os contextos históricos houve exploração de mão-de-obra infantil em atividades econômicas produtivas por parte de empregadores, sejam em grandes ou pequenas empresas, nos grandes centros ou em áreas rurais e, às vezes, muitos benefícios desse trabalho foram adquiridos por meio da exploração daquelas famílias que se encontravam em situação de maior exclusão social.

Ao associarmos a essas discussões sobre o trabalho infantil ponderações sobre a escola podemos dizer que acesso à educação e mundo do trabalho sempre estiveram nas pautas de discussão da legislação brasileira; porém, nem sempre "do mesmo lado". Se considerarmos essa análise a partir de um ponto de vista histórico, podemos dizer que a educação formal ministrada pelos jesuítas era destinada às crianças brancas, enquanto às indígenas cabia a catequese, às negras a formação para o trabalho e às pobres, filhas de imigrantes e da zona rural, não cabia educação alguma, pois acreditava-se que essas não precisavam de escolas (MANTOVANI, 2017).

Percebemos, assim, que a educação assumiu um caráter de exclusão no país, organizada por um sistema dual de ensino, dividido em "tradicional" para os ricos e "profissionalizante" para os pobres. Com esse legado histórico e cultural de exclusão e marginalidade das camadas populares dos bancos escolares, o trabalho configurou-se como natural, viável e parte importante do processo de socialização de crianças e adolescentes (LIMA, 2009; MANTOVANI, 2017). Tendo em vista tais ponderações, traçamos como objetivo desse estudo compreender a relação entre trabalho infantil e escola a partir da fala de adultos com histórico de trabalho infantil, estudantes em turmas de Educação de Jovens e Adultos.

\section{METODOLOGIA}

Essa pesquisa está ancorada em uma abordagem quanti-qualitativa, caracterizada por um estudo exploratório descritivo. Para Minayo (2010, p. 57), "o método qualitativo é o que se aplica ao estudo da história, das relações, das representações, das crenças, das percepções e das opiniões, produtos das interpretações que os humanos fazem a respeito de como vivem, constroem seus artefatos e a si mesmos, pensam e sentem".

No seio dessa perspectiva, o estudo exploratório descritivo é definido por Triviños
(2009, p. 110) como um estudo que permite ao investigador aumentar sua experiência em torno de determinado problema partindo de uma hipótese para, em seguida, buscar conhecimentos mais amplos que descrevam "com exatidão os fatos e fenômenos de determinada realidade". Dessa forma, adotamos essa abordagem de pesquisa por ser a mais indicada para os propósitos que traçamos. Ressaltamos, ainda, que essa pesquisa passou por avaliação de um Comitê de Ética em Pesquisa e obteve parecer favorável a sua realização (Protocolo número 27080814.6.00005402), tendo em vista que contou com a participação de seres humanos.

\section{RESULTADOS}

Serão apresentados dados referentes aos aspectos sociodemográficos (sexo, idade e renda mensal) e à escolaridade (idade, série e motivo(s) pelos quais parou de estudar na infância/adolescência) dos participantes. Assim, dos 131 participantes do estudo, 53,4\% eram mulheres e $46,6 \%$ eram homens, revelando a idade mínima de 21 e a máxima de 72 anos para mulheres $(38,24 \pm 9,86)$ e para os homens a idade mínima também foi 21 anos com a máxima de 60 $(39,59 \pm 10,53)$.

Quando consideramos os ganhos mensais, podemos perceber que a maior porcentagem de sujeitos encontra-se na faixa salarial entre $\$ 725,00$ e $\$ 1448,00(33,6 \%)$, ou seja, de um a dois salários mínimos, tendo em vista que o valor mensal atribuído ao salário mínimo no Brasil à época da elaboração do questionário e da pesquisa de campo era de $\$ 724,00$ (BRASIL, Decreto 8.166/2013). É significativa a frequência de sujeitos que tem uma renda mensal superior a três salários mínimos $(26,0 \%)$, outros que obtém uma renda mensal de até um salário mínimo (15,3\%) e aquele que não possui renda alguma $(0,8 \%)$.

Quanto à escolarização, $28,2 \%$ dos participantes afirmaram que deixaram a escola quando tinham de 11 a 14 anos de idade, seguidos daqueles entre 15 e 17 anos $(24,4 \%)$ e que se encontravam abaixo dos 10 anos $(16,8 \%)$. Junto a isso, notamos que a maioria dos participantes parou de estudar no Ensino Fundamental II - 5a a 8a série - (47,3\% dos casos), seguida de 24,4\% no Ensino Médio; 22,9\% no Ensino Fundamental I - 1a a 4a série - e apenas $0,8 \%$ que não frequentou a escola. 
Tendo em vista a idade que começou a trabalhar e a série em que parou os estudos, os participantes também puderam elencar o(s) motivo(s) que os afastaram da escola, destacando-se que para $56,5 \%$ deles foi o trabalho o principal motivo que implicou no afastamento dos estudos durante a infância/adolescência. Também surgiu aquele fator classificado como "outros" em 27,5\% dos casos, que englobou acidente, alcoolismo do pai, casamento, cirurgia, dificuldade em entender os professores, doença, falecimento da mãe/dos pais, falta de incentivo dos pais, falta de permissão do pai para o estudo, gravidez, medo da violência, nascimento/filhos pequenos, seções de fisioterapia e teatro.

Com frequências muito próximas os participantes assinalaram as alternativas referentes à falta de interesse $(16,8 \%)$; a morar na área rural (16\%); a morar longe da escola $(14,5 \%)$ e à mudança de bairro/escola/cidade $(11,5 \%)$, obtendo menores porcentagens a falta de dinheiro $(7,6 \%)$ e a qualidade da escola $(0,8 \%)$. O nível de formação dos professores não foi um motivo que contribuiu para que os participantes parassem os estudos durante sua infância/adolescência, embora tenham registrado como "outros motivos" a dificuldade em entender os professores.

\section{DISCUSSÃO}

Ao olharmos para a idade dos participantes, notamos que as pessoas mais velhas são aquelas menos escolarizadas, principalmente quando consideramos os dados relativos às mulheres, que amargam a dura realidade de não poderem estudar. Por outro lado, esses dados também reforçam um aspecto que tem sido notado em outras realidades, quando pessoas cada vez mais novas são encaminhadas para turmas de EJA. Para Haddad (2007) o processo de juvenilização do Ensino Supletivo e de outros cursos de EJA na América Latina, antes indicados para indivíduos adultos e idosos que não tiveram acesso à escolarização na idade certa, se deve ao fato de que essa modalidade de ensino está se constituindo por grande procura de pessoas mais novas, excluídas da escola, em alguns casos, justamente pela necessidade de trabalhar para ajudar na renda familiar.

Quando consideramos os adultos trabalhadores da EJA é necessário considerar, ainda, as dificuldades que o sistema escolar tem em atender esse alunado com qualidade $\mathrm{e}$ adequação aos seus interesses, não apenas para alcançarem objetivos estritamente econômicos, mas para garantir sua participação social, política e cultural. O modelo escolar vigente se distancia desse público, que é diferente e precisa de professores com formação específica, de escolas com estruturas diferentes e que deem conta das expectativas que têm, dado que possuem um leque de conhecimento pouco aproveitado durante as aulas, têm projetos para sua vida presente e futura e buscam suprir necessidades educacionais específicas (MANTOVANI, 2017).

Junto a esses dados, quando cruzamos a idade em que o sujeito ingressou no mercado de trabalho com a série em que parou os estudos notamos que esses respondentes começaram a trabalhar na faixa etária (11 aos 14 anos) de maiores registros de crianças e adolescentes em situações de trabalho (ALBERTO, et al. 2011; LIBÓRIO, 2009), bem como deixaram a escola durante o período considerado como educação básica obrigatória atualmente, que vai dos 04 aos 17 anos de idade no Brasil, conforme prescrições do Artigo 208, Inciso I, da Constituição Federal (BRASIL, 1990): “Educação Básica obrigatória e gratuita dos 4 aos 17 anos de idade, assegurada inclusive sua oferta gratuita para todos os que a ela não tiveram acesso na idade própria" (EMENDA CONSTITUCIONAL no 59, de 2009).

Esses dados nos revelam, ainda, que o trabalho contribuiu significativamente para a saída dos participantes da escola na época de sua infância/adolescência (ALVES-MAZZOTTI, 1998). Todavia, um conjunto de fatores, também extraescolares, como falta de interesse, morar na área rural/longe da escola, mudança e falta de dinheiro, fez com que a saída da escola ultrapassasse os limites legais vigentes. É possível vermos que o trabalho foi a causa principal para a saída da escola, porém, não foi a única.

\section{CONCLUSÃO}

Buscamos contemplar nesse estudo alguns pontos que fazem parte das nossas inquietações quanto à relação entre trabalho infantil e escola. Diante dessas proposições, foi possível notar que buscamos uma discussão sobre o trabalho infantil que considera o ponto de vista do próprio sujeito trabalhador sobre sua situação, a análise cultural e contextual sobre sua ocorrência e os fatores que encaminham para a necessidade de inserção precoce no mercado de trabalho. Por outro lado, também acreditamos 
ser necessária uma análise que investiga a qualidade da educação oferecida, as formas de acesso e permanência disponíveis aos trabalhadores e como se dá o desempenho do aluno nos estudos.

Nossa intenção é analisar o trabalho infantil para além de uma visão generalista e universalista, que desconsidera as necessidades financeiras da família, o valor atribuído à escola pela família e comunidade, àquilo que ela representa para o estudante em geral e para aquele que trabalha e suas famílias, de uma forma particular, e quais são os interesses e necessidades dessa população. $O$ trabalho infantil é um fenômeno multidimensional, que deve ser problematizado a partir de elementos paradoxais, uma vez que pode estar associado a interpretações ora positivas ora negativas por parte dos sujeitos trabalhadores, além dos sentidos pessoais que carrega. Também não podemos nos esquecer que o trabalho infantil é gerado por uma sociedade excludente e desigual, além de estar envolto a aspectos culturais que tendem a valorizar o trabalho (discurso ideológico) como fator que dignifica o homem.

\section{REFERÊNCIAS}

ALBERTO, M. F. P. et al. O trabalho infantil doméstico e o processo de escolarização. Psicologia \& Sociedade, Belo Horizonte, v. 23, n. 2, p.293-320, 2011. Disponível em: https://doi.org/10.1590/S0102-

71822011000200010. Acesso em 20 abr. 2017.

ALVES-MAZZOTTI, A. J. Trabalho infanto-juvenil: representações de meninos trabalhadores, seus pais, professores e empregadores. In: MOREIRA, A. S. P.; OLIVEIRA, D. C. (Orgs.). Estudos interdisciplinares de representação social. Goiânia: AB, 1998, p. 285-301.

HADDAD, S. A ação de governos locais na Educação de Jovens e Adultos. Revista Brasileira de Educação, Rio de Janeiro, v. 12 n. 35, p. 197211, maio/ago. 2007.

LIBÓRIO, R. M. C. Crianças e Adolescentes em situação de risco: dimensões do trabalho infantil nos municípios de Presidente Prudente, Belo Horizonte e Porto Alegre. 2009. Relatório de pesquisa não publicado (enviado ao CNPq).

LIMA, M. F. Mulheres têm papel importante nas mudanças da sociedade brasileira. Postado em
19 de outubro de 2009. Disponível em http://maurilioferreiralima.com.br/2009/10/mul heres-tem-papelimportante-nasmudancasdasociedade-brasileira/. Acesso em: 15 maio 2015.

MANTOVANI, A. M. Trabalho infantil e resiliência na vida de estudantes da EJA. 2017. 221f. Tese (Doutorado em Educação) - Faculdade de Ciências e Tecnologia, Universidade Estadual Paulista, Presidente Prudente/SP, 2017.

MYNAIO, M. C. S. (Org.). Pesquisa social: teoria, método e criatividade. 29. ed. Petrópolis,RJ: Vozes, 2010.

STROPASOLAS, V. L. Trabalho Infantil no campo: do problema social ao objeto sociológico. Revista Latino-Americana de Estudos do Trabalho, v. 17, n. 27, p. 249-286, 2012.

TRIVIÑOS, A. N. S. Introdução à pesquisa em ciências sociais: a pesquisa qualitativa em educação. São Paulo: Atlas, 2008.

Recebido para publicação em: 30/05/2017

Revisado em: 08/06/2017

Aceito em: 21/06/2017 